\title{
Predicting Academic Procrastination and Academic Achievement in Private Higher Education With the HEXACO Model of Personality and Psychological Distress
}

\author{
Katarina Sokić ${ }^{1}$, Fayyaz Hussain Qureshi $^{1} \&$ Sarwar Khawaja ${ }^{1}$ \\ ${ }^{1}$ Oxford Business College, 65 George Street, Oxford, United Kingdom \\ Correspondence: Fayyaz Hussain Qureshi, Oxford Business College, 65 George Street, Oxford, United Kingdom. \\ E-mail: fayyaz.qureshi@oxfordbusinesscollege.ac.uk
}

Received: December 7, 2021

Accepted: December 31, 2021

Online Published: January 4, 2022

doi:10.5430/irhe.v6n4p29

URL: https://doi.org/10.5430/irhe.v6n4p29

\begin{abstract}
Academic procrastination is one of the main problems in the private higher education sector associated with a high rate of abandonment of higher education and delays in fulfilling student obligations. In an effort to detect some of the personal predictors of this phenomenon, we examined associations between personality traits, psychological distress, academic procrastination, and academic achievement among students in private higher education. A sample of 369 participants (145 men, 224 women, 23 years on average) was taken. Participants self-reported their academic achievement and anonymously completed several questionnaires: The Studying Procrastination Scale, The Depression Anxiety Stress Scales - 21, the HEXACO Personality Inventory-Revised - 60. In line with prediction, the HEXACO dimensions explained an additional $24 \%$ of the variance in academic procrastination after controlling for psychological distress. In addition, Conscientiousness and psychological distress predicted academic procrastination, and Conscientiousness uniquely significantly predicted academic performance. Our results suggest that academic procrastination and academic performance are influenced by personality. Also, this study indicated that the impact of psychological distress on academic outcomes depends on the constellation of personality traits. Current findings could help to better understand personal factors associated with negative academic outcomes and prevent negative emotional states associated with student procrastination and poor academic performance.
\end{abstract}

Keywords: academic procrastination, academic achievement, private higher education, HEXACO, psychological distress

\section{Introduction}

Procrastination is the conscious prorogation of the beginning or completion of an obligation despite the expectation of harmful consequences due to delay (Abbasi \& Alghamdi, 2015; Gupta et al., 2012; Milgram et al., 1998). Procrastination is a form of behaviour associated with adverse physical and mental health outcomes such as greater stress vulnerability, non-effective time management, reduced performance levels, delayed study obligations, high levels of frustration, and problems regulating negative emotions (Ferrari \& Díaz-Morales, 2014).

Studies have shown that procrastination in everyday life affect $20-25 \%$ of men and women in everyday events (e.g., paying bills and taxes, undergoing medical examinations), which highlights that procrastination is characteristic of modern societies (Rosário et al., 2009; Sirois \& Pychyl, 2013). Procrastination is often related to reduced insight into the consequences of current behaviour, short-term mood repair, and problems with emotion regulation (Sirious, 2013). The present study focuses on academic procrastination in higher private education as one of the specific types of procrastination (Balkis \& Duru, 2007). Academic procrastination, also called the "endemic problem among college students", is related to delaying students' activities relevant to fulfilling student duties and obligations, particularly learning and taking exams on time (Milgram et al., 1995). Academic procrastination is defined as students postponing their academic responsibilities such as doing homework, studying for exams, writing term papers, or performing academic administrative and attendance tasks to the last possible minute (Schouwenburg et al., 2004). Steel \& Klingsieck (2016, p. 37) redefine the term academic procrastination as "to voluntarily delay an intended course of study-related action despite expecting to be worse off for the delay". Academic procrastination was influenced by different personal, social, and situational factors such as personality traits, self-regulation, coping 
with stress, and self-efficacy, self-handicapping (Van Earde, 2003). Although procrastination occurs in all parts of daily life (Alexander \& Onwuegbuzie, 2007), the frequency of academic procrastination is more pronounced than other types of procrastination. Rabin et al. (2011) found that 30-60\% of undergraduate students regularly postpone academic assignments. Another study has shown that only $3 \%$ of university students are not affected by the different effects of procrastination, and half of them often or always procrastinate (He, 2017).

The results of meta-analysis synthesized results of 33 research studies, and a total of 38,529 participants (Kim \& Seo, 2015) revealed that academic procrastination negatively correlated with academic performance and that the choice of procrastination measure influenced the association between procrastination and academic procrastination performance. Previous findings have shown low negative relationships between self-reported academic procrastination and academic achievement (e.g., Balkis, 2011; Hen \& Goroshit, 2014). Namely, self-reported procrastination was higher than procrastination measured externally, indicating that participants reinforce the dimensions for delay of their academic performance. Also, the results indicate that delaying should be more negatively interpreted in individualistic westernized societies (e.g., America, Europe, and Australia) compared to collectivist cultures. The significant negative relationship between academic performance (i.e., final exam and measures of online course participation) and academic procrastination was found in a study conducted by Goroshit (2018).

Studies that examined sociodemographic, behavioural, and neurobiological predictors of procrastination showed that men procrastinate more than women (Steel \& Ferrari, 2013), and the procrastination significantly rises during undergraduate schooling and reaches its highest point in the mid-twenties (Schubert \& Stewart, 2000). Procrastination shares similar attributes with attention deficit hyperactivity disorder (ADHD), including distractibility, impulsivity, and lack of proper planning and control (Nguyen et al., 2013). Furthermore, chronic, long-term procrastination is related to poor physical and mental health due to a higher level of perceived stress and unsuccessful coping with the behavioural patterns of procrastination (Ferrari \& Díaz-Morales, 2014). In addition to the factors mentioned above influencing procrastination, studies consistently showed that personality is one of the most stable and significant predictors of procrastination (Milgram, \& Tenne, 2000; Schouwenburg \& Lay, 1995). All of these studies examined the relationship of procrastination within the well-known Five-Factor (Big Five) model of personality, which encompasses five personality traits: neuroticism, extraversion, openness, agreeableness, and conscientiousness (McCrae \& Costa, 1987).

To the best of our knowledge, the relationship between the HEXACO model of personality (Lee \& Ashton, 2004), academic procrastination, and academic achievement is not investigated. The HEXACO model of personality (Lee \& Ashton, 2004; Ashton et al., 2014) is a relatively new model which is increasingly used in personality research. This model includes a dimension labelled honesty-humility that relates to stability, organization, and responsibility, the features presumed to be relevant to academic procrastination. Therefore, in this study, we will examine associations between HEXACO dimensions: honesty-humility, emotionality, extraversion, agreeableness, conscientiousness, and openness to experience, psychological distress, academic procrastination, and academic achievement. Besides, we will investigate the contribution of the HEXACO dimensions in predicting academic procrastination and academic achievement beyond psychological distress.

\section{Literature Review}

\subsection{Personality and Academic Procrastination}

The Big Five-Factor Model (Goldberg, 1990; Goldberg, 1993) indexed by the Revised NEO Personality Inventory (Costa \& McCrae, 1992) which is one of the most dominant models of personality, includes five personality domains: neuroticism, extraversion, openness to experience, agreeableness, and conscientiousness. Milgram \& Tenne (2000) found that conscientiousness and openness to experience are predictive of academic procrastination. Conscientiousness and self-discipline were unique negative predictors of procrastination in a study on undergraduate students conducted by Steel \& Klingsieck (2015). Irfan et al. (2015) was found a negative association between conscientiousness, agreeableness, openness and procrastination. In this study, extraversion and neuroticism are positively correlated to procrastination. A recent study conducted by Sandhya \& Gopinath (2019) on college students within Delhi has shown a significant relationship between neuroticism, conscientiousness, and extroversion, and intentional decision in active procrastination. In this study, conscientiousness and extroversion were significantly related to preference for pressure, while agreeableness and openness were related to irrational decisions. As we can see, relations between the Big Five-Factor model of personality and academic procrastination are relatively well explored, but findings are often contradictory and inconsistent because different procrastination measures were used.

Bearing in mind the above discrepancies in findings, personality will be measured using the HEXACO model in this 
study. This model is largely similar to the well-known Five-Factor (Big Five) model of personality (McCrae \& Costa, 1987). However, relative to the Big Five model, the HEXACO model encompasses a larger overall personality space and has better cross-cultural validity (Ashton \& Lee, 2007; Lee \& Ashton, 2008). The key difference is that the HEXACO model includes a sixth broad factor, termed Honesty-Humility, encompassing pro-social behaviour. Also, the emotionality dimension of the HEXACO model includes facets of fearfulness. This facet was not represented in the neuroticism dimension of the Big Five. Fearfulness encompasses the tendency to experience fear and potential value for indexing procrastination related to problems regulating negative emotions, including fear and excessive concern (Ferrari \& Díaz-Morales, 2014). The relationship between academic procrastination and the HEXACO model is of particular interest; however, there has been no published work as yet regarding this relationship. Additionally, as Svartal et al. (2020) suggested, future investigations association between students' individual characteristics and contextual factors (i.e., education institutions, study programs, and professors) are vital for developing prevention/interventions programs concerning procrastination.

\subsection{Psychological Distress and Academic Procrastination}

Empirical studies consistently have shown a positive relationship between academic procrastination and negative affective consequences such as stress, depression, anxiety, and fear (e.g., Grunschel et al., 2013; Lay \& Silverman, 1996; Pychyl et al., 2000; Tice \& Baumeister, 1997). Findings showed that students are more procrastinating on academic tasks that they perceive to be difficult (e.g., learning, homework) (Ferrari \& Scher 2000), and that depression is positively related to a tendency to avoid problems and procrastination, independent of symptoms of anxiety (Fernie et al., 2017; Steel, 2007). The study which examined the prevalence of academic procrastination among different categories of students: undergraduate, postgraduate taught (Masters), and postgraduate research (PhD.) in the University of Bristol (He, 2017), has shown that $84 \%$ of undergraduates, and about $90 \%$ postgraduates felt anxiety during procrastination. Also, stress among students has expressed that $41 \%$ of undergraduates and about $50 \%$ of postgraduates were under stress. Related to negative emotional states, this study also showed that about $70 \%$ of students tend to drink alcohol more when they procrastinate. The link between psychological distress and procrastination was found in undergraduate students at a Canadian university (Constantion et al., 2018). Procrastination was positively correlated with anxiety, depression, worry, and rumination (i.e., obsessional thinking involving excessive, repetitive thoughts or themes that interfere with other forms of mental activity). Given that these findings, it appears that there is a positive relationship between experiencing negative emotional states, such as anxiety, depression, and stress, and engaging in academic procrastination.

\subsection{Personality and Academic Achievement}

Some authors consider that personality is not crucial for academic success (e.g., Allik \& Realo, 1997; Dollinger \& Orf, 1991). Instead, cognitive ability is a significant predictor of academic achievement. The association between cognitive ability and academic achievement has been well demonstrated (e.g., Brody, 2000; Jensen, 1980; Kuncel et al., 2001; Zeidner \& Matthews, 2000). However, numerous studies suggested that both cognitive abilities and personality traits are significant predictors of academic success (e.g., Furnham et al., 2002; Furnham \& Chamorro-Premuzic, 2003). Cognitive abilities enable understanding and learning - they refer to what a person can do, while personality traits can improve or harm the use of these abilities and relate to how a person does something. Given this finding, personality traits explain the variance of academic performance, especially in higher education, where the link between cognitive abilities and academic success was somewhat smaller than at lower levels of education (Chamorro-Premuzic \& Furnham, 2003a). In addition, research has shown a negative association between neuroticism and academic success (Chamorro-Premuzic \& Furnham, 2003). Also, findings indicate that conscientiousness is the most significant and most important predictor of academic success among students (Chamorro-Premuzic \& Furnham, 2003; Furnham et al., 2003; Furnham \& Chamorro-Premuzic, 2002).

Some authors consider that personality is not crucial for academic success (e.g., Allik \& Realo, 1997; Dollinger \& Orf, 1991). Instead, cognitive ability is a significant predictor of academic achievement. The association between cognitive ability and academic achievement has been well demonstrated (e.g., Brody, 2000; Jensen, 1980; Kuncel et al., 2001; Zeidner \& Matthews, 2000). However, numerous studies suggested that The relationship between some dimensions of the HEXACO model of personality and academic performance is not sufficiently examined. Khan \& Sarwar (2016) demonstrated a positive relationship on a bivariate level between academic performance (measured by class tests, exam papers, group projects, and total marks), conscientiousness, and its facet organization and prudence. This study showed positive correlations between the liveliness facet of extraversion and some measured of academic performance (i.e., class tests and exam papers), and a positive correlation between openness to experience and group projects. Noftle \& Robins (2007) has shown that the HEXACO dimension of conscientiousness was associated with 
higher college grades and higher grade-point average. The HEXACO openness to experience was positively related to the Scholastic Assessment Test (SAT). The SAT is the most widely used measure of academic potential, and it plays a key role in enrollment at most universities in the USA. A recent study (Mahmood et al., 2021) has shown that consciousness is related to the studies' deep learning and intrinsic motivation, while neuroticism is negative related to learning and academic motivation. As we have seen, some research has partially examined specific aspects of academic achievement within the HEXACO model. However, it is necessary to examine the predictive power of the dimensions of the HEXACO model concerning academic achievement among the student population.

\subsection{Present Study: Aims and Hypotheses}

The present study aims to examine the role of HEXACO personality traits and psychological distress in academic procrastination and academic performance in private higher education. The above-reviewed literature showed that the HEXACO personality traits in predicting academic procrastination and academic performance are not examined. Also, it is not clear whether HEXACO personality traits outperformed psychological distress in predicting academic procrastination and academic performance.

Based on the theory that honesty-humility assesses the tendency to be modest and genuine (Lee \& Ashton, 2004), and empirical evidence of the significant negative association between honesty-humility and risky behaviours (Casini et al., 2018; de Vrie et al., 2011), we expect that honesty-humility will be negatively related to academic procrastination (Hypothesis 1).

In line with empirical evidence of the significant positive correlation between honesty-humility and grade point average (de Vries et al., 2011), we expect honesty-humility to be positively related to academic performance (Hypothesis 2). Based on the theory that emotionality assesses a tendency to experience fear, worry, and stress (Lee \& Ashton 2004), and empirical evidence of the significant positive associations between emotionality and neuroticism (Ashton et al., 2014). Therefore, we expect a positive correlation between emotionality and academic procrastination (Hypothesis 3).

Based on the theory that conscientiousness assesses a tendency to work hard, and concerned with details as a well-structured approach to tasks and good self-control (Lee \& Ashton 2004), and empirical evidence of the negative associations between conscientiousness and academic procrastination (de Vries et al. 2011), we expect that conscientiousness will negatively correlate with academic procrastination (Hypothesis 4). Based on evidence that conscientiousness is positively associated with academic performance (de Vries et al., 2011; Khan \& Sarwar, 2016), and achievement (Anglim et al., 2017), we expect that this personality dimension will be positively related to academic performance (Hypothesis 5).

Since procrastination is linked to negative emotional states (e.g., Grunschel et al., 2013; Tice \& Baumeister, 1997), and in line with findings that psychological distress is positively related to procrastination (Constantion et al., 2018), we expect that psychological distress will be positively related to academic procrastination (Hypothesis 6).

We hypothesise that, due to the positive relation of conscientiousness to positive academic outcomes (de Vries et al., 2011; Khan \& Sarwar, 2016), conscientiousness will be the primary predictor of both academic procrastination and academic performance (Hypothesis 7). Also, we predict that associations between personality traits and academic procrastination will be significant even when psychological distress is partially out and included in the regression (Hypothesis 8).

\section{Methodology}

\subsection{Participants}

The participants in this study were 349 undergraduates (145 men, 224 women) from private higher education institutions located in Zagreb, Croatia. Students were asked to self-report on their academic success in studies. The mean age of the sample was 23 years $(\mathrm{SD}=5.69$; range $=20-29$ years). All participants were in their second and third year of study. The questionnaires were administered during studies class with the permission of the course lecturers, and students were familiar that they could give up from the research at any time.

\subsection{Measures}

\subsubsection{The HEXACO Personality Inventory-Revised}

The HEXACO Personality Inventory-Revised (HEXACO-60; Ashton \& Lee, 2009, for the Croatian version, see Babarović \& Šverko, 2013) is a short version of HEXACO-PI-R that assesses the six dimensions of the lexical HEXACO personality model: honesty-humility, emotionality, extraversion, agreeableness, conscientiousness and openness to experience. Each dimension contains of 10 items which are presented in 5-point Likert-type format 
(from $1=$ strongly disagree to $5=$ strongly agree. Reliabilities are presented in Table 1 . Items are rated on a 5 -point Likert scale ranging from 1 (strongly disagree) to 5 (strongly agree). Cronbach's $\alpha$ coefficient in the current study ranged from .73 to .79 .

\subsubsection{Depression Anxiety and Stress Scales-21}

The Depression Anxiety Stress Scales - 21 (DASS-21; Lovibond \& Lovibond, 1995) is a self-report instrument that contains 21 items and measures negative emotional states of depression, anxiety, and stress on a four-point Likert scale $(0=$ did not apply to me at all to $3=$ applied to me very much, or most of the time). The stress scale assesses feelings of irritability and tension, the anxiety scale assesses fear and anxious pathology (e.g., panic attack), and the depression scale assesses symptoms of dysphoric mood. The subscales have high internal consistencies with Cronbach's alphas for depression of $.94, .87$ for anxiety and .91 for stress, and good concurrent validity. The items are scored According to the CFA results, the hierarchical one-factor model of psychological distress proved to be the most acceptable $\left(\chi^{2}[\mathrm{df}=89]=240.88, \mathrm{p}<0.01 ; \mathrm{NC}=2.71 ; \mathrm{SRMR}=0.04 ; \mathrm{CFI}=0,96 ; \mathrm{IFI}=0.96\right.$; TLI $=0.95$; RMSEA $=0.08)$, with two highly correlated dimensions of anxiety and stress $(r=0.67, p<0.01)$. Alpha reliabilities of the DASS-21 total score was .84.

\subsubsection{The Studying Procrastination Scale}

The Studying Procrastination Scale (Wohl, et al., 2010) is a self-report instrument consisting of three items on a seven-point Likert scale, from 1 (strongly disagree) to 7 (strongly agree). An example of scale items is: "I delayed preparing for the exam by doing other, less important things instead". Cronbach's $\alpha$ coefficient for this scale was .91 .

\subsection{Research Design and Statistical Analysis}

Descriptive and correlational analyses were performed. The predictive power of the HEXACO traits and psychological distress in explaining academic procrastination and academic achievement was tested by hierarchical regressions analyses. Gender and age were entered in Step 1, six HEXACO dimensions were entered at Step 2, and a total score on psychological distress was entered at Step 3. In all regression analyses, we used two-sided statistical significance criteria.

\section{Results}

\subsection{Descriptive Statistics and Correlation Analysis}

As we can see in Table 1, all scales showed an adequate range and internal psychometric characteristics. Alpha reliabilities for all scales were more than .70 (from .73. for agreeableness to .91 for academic procrastination). Also, skewness and kurtosis for all scales were within the acceptable bounds between -2 to +2 .

Table 1. Descriptive statistics and internal consistency values $(n=349)$

\begin{tabular}{llllllll}
\hline & $M$ & $S D$ & $\begin{array}{l}\text { Maximal } \\
\text { range }\end{array}$ & $\begin{array}{l}\text { Actual } \\
\text { range }\end{array}$ & $\alpha$ & Skew. & Kurt. \\
\hline Honesty-Humility & 29.19 & 7.78 & $10-50$ & $14-47$ & .77 & -0.39 & 0.40 \\
Emotionality & 26.67 & 5.46 & $10-50$ & $12-49$ & .74 & 0.01 & -0.30 \\
Extraversion & 33.23 & 4.61 & $10-50$ & $15-50$ & .75 & -0.33 & 0.45 \\
Agreeableness & 30.80 & 5.37 & $10-50$ & $11-46$ & .73 & -0.03 & -0.19 \\
Conscientiousness & 32.63 & 5.89 & $10-50$ & $13-45$ & .75 & -0.32 & 0.38 \\
Openness to experience & 32.71 & 6.07 & $10-50$ & $11-50$ & .79 & -0.01 & -0.11 \\
Psychological distress & 43.19 & 9.32 & $0-63$ & $13-59$ & .84 & 0.48 & 0.10 \\
Academic procrastination & 14.28 & 3.11 & $3-21$ & $3-21$ & .91 & -0.11 & -0.61 \\
Academic performance & 3.43 & 0.64 & $1-5$ & $2-5$ & $\mathrm{n} / \mathrm{a}$ & -0.02 & 0.41 \\
\hline
\end{tabular}

Note: $\alpha=$ Cronbach's $\alpha$

Bivariate correlations between the HEXACO dimensions were low to moderate, in line with previous findings (de Vries et al., 2011; Sokić et al., 2019). As predicted (Hypothesis 1), the honesty-humility negatively correlated with academic procrastination $(\mathrm{r}=-.17, \mathrm{p}<.01)$. Unexpected (see Hypothesis 2 ), the honesty-humility was unrelated to academic performance $(r=.08, \mathrm{p}>.05)$. Hypothesis 3 has not been confirmed given that emotionality was unrelated 
to academic procrastination. However, on the bivariate level emotionality significantly positively correlated with psychological distress $(r=.23, \mathrm{p}<.01)$. In line with Hypothesis 4 , conscientiousness significantly negatively correlated with academic procrastination $(\mathrm{r}=-.46, \mathrm{p}<.01)$. As expected, conscientiousness was positively related to academic performance $(\mathrm{r}=.17, \mathrm{p}<.05)$, which is in line with Hypothesis 5 . Unexpected psychological distress was unrelated to academic procrastination (Hypothesis 6). However, all HEXACO traits showed significant associations with psychological distress. Results have shown negative correlations between psychological distress and honesty humility, extraversion, agreeableness, conscientiousness, and openness to experience on a bivariate level. Also, we found a positive bivariate correlation between psychological distress and emotionality.

Table 2. Zero order correlations between explored variables $(n=349)$

\begin{tabular}{lccllllll}
\hline & 1. & 2. & 3. & 4. & 5. & 6. & 7. & 8. \\
\hline 1. Honesty- Humility & - & & & & & & & \\
2. Emotionality & .11 & - & & & & & & \\
3. Extraversion & -.01 & -.08 & - & & & & & \\
4. Agreeableness & $.35^{* *}$ & -.08 & .05 & - & & & & \\
5. Conscientiousness & $.25^{* *}$ & .02 & $.21 * *$ & .06 & - & & & \\
6. Openness to experience & $.16^{*}$ & .02 & $.14^{*}$ & $.15^{* *}$ & $.16^{* *}$ & - & & \\
7. Psychological distress & $-.33^{* *}$ & $.23^{* *}$ & $-.49 * *$ & $-.51^{* *}$ & $-.30^{* *}$ & $-.16^{*}$ & - & \\
8. Academic procrastination & $-.17^{* *}$ & -.06 & -.01 & -.05 & $-.46^{* *}$ & -.01 & .13 & - \\
9. Academic performance & .08 & -.02 & -.08 & .06 & $.17^{*}$ & -.02 & -.13 & $-.25^{* *}$ \\
\hline
\end{tabular}

Note. $* p<.05, * * p<.01$.

\subsection{Hierarchical Linear Regression Analyses}

Results of hierarchical regression analyses (see Table 3) showed that psychological distress positively predicted academic procrastination in the second step of hierarchical linear regression analyses $(\beta=.15, \mathrm{p}<.01)$ and explained $2 \%$ of the variance in academic procrastination $(\mathrm{F} \Delta(1,395)=3.86, \mathrm{p}<.05)$ which is in line with Hypotheses 6. Furthermore, in line with Hypothesis 7, conscientiousness significantly predicted academic procrastination $(\beta=$ $-.53, \mathrm{p}<.001)$, and academic achievement $(\beta=.21, \mathrm{p}<.01)$ while other HEXACO dimensions are not significant predictors of academic procrastination.

Table 3. Hierarchical linear regression analysis: prediction of academic procrastination and academic performance based on HEXACO-60 and DASS-21 $(n=349)$

\begin{tabular}{lllllll}
\hline & \multicolumn{3}{l}{ Academic procrastination } & \multicolumn{3}{l}{ Academic performance } \\
\hline Step 1 & $\mathrm{B}$ & $\beta$ & $t$ & $\mathrm{~B}$ & $\beta$ & $t$ \\
Gender & & & & & & \\
Age & -.31 & -.05 & -.67 & .15 & .10 & .92 \\
$R^{2}$ & .06 & .06 & .81 & -.01 & -.03 & -.27 \\
Step 2 & .01 & & & .01 & & \\
Gender & & & & & & \\
Age & -.45 & -.07 & -.98 & .18 & .12 & 1.06 \\
Psychological distress & .05 & -.05 & .62 & -.02 & -.04 & -.39 \\
$\Delta R^{2}$ & .03 & $.15 *$ & 1.97 & -.01 & -.15 & -1.36 \\
Step 3 & $.02 *$ & & & .02 & & \\
Gender & & & & & & .70 \\
Age & .24 & .04 & .49 & .14 & .09 & -.66 \\
Psychological distress & .13 & .13 & 1.92 & -.03 & -.07 & -1.01
\end{tabular}




$\begin{array}{lllllll}\text { Honesty- Humility } & -.01 & -.04 & -.54 & .01 & .16 & 1.32 \\ \text { Emotionality } & .00 & .01 & .09 & -.01 & -.10 & -.80 \\ \text { Extraversion } & .03 & .08 & 1.03 & -.03 & -.18 & -1.00 \\ \text { Agreeableness } & -.01 & -.02 & -.20 & -.01 & -.03 & -.23 \\ \text { Conscientiousness } & -.20 & -.53 * * * & -7.24 * * * & .02 & .21^{*} & 1.78^{*} \\ \text { Openness to experience } & .03 & .08 & 1.23 & -.01 & -.03 & -.25 \\ \Delta R^{2} & .24 * * * & & & .13^{*} & & \\ \text { Total } R^{2} & .27 * * * & & & .16^{*} & & \end{array}$

Note. $* p<.05, * * p<.01, * * * p<.001$ (two-tailed).

Results showed (Table 3) that personality has incremental validity in predicting academic procrastination and that psychological distress became insignificant when personality dimensions were entered as predictors. Namely, personality dimensions explained an additional $24 \%$ of the variance in academic procrastination after controlling for psychological distress in the third step hierarchical linear regression analyses $(\mathrm{F} \Delta(1,345)=9.77, \mathrm{p}<.001)$, thus confirming Hypothesis 8. Results of hierarchical regression analyses have shown that predictors together explained $27 \%$ of the variance in academic procrastination and $16 \%$ of the variance in academic performance.

\section{Discussion}

This study was explored the effects of the HEXACO personality dimensions and psychological distress in academic procrastination and academic performance. Our findings suggest that the impact of HEXACO personality traits on academic procrastination academic performance and performance are independent of psychological distress. These results emphasize the importance of personality traits in achieving academic success and overcoming negative emotional states that can lead to unwanted outcomes.

As expected, results showed that honesty-humility negatively correlated with academic procrastination, which is in line with findings that honesty-humility is unrelated to risk behaviour characteristic of procrastination (Casini et al., 2018; de Vries et al., 2011). This finding further confirms that honesty-humility is an adaptive personality trait that was not included in the previous taxonomy of personality and can be a useful predictor of different academic outcomes in future research. Although an earlier study showed that honesty-humility positively related to grade point average (de Vries, 2011), in this study, honesty-humility was unrelated to academic performance. This discrepancy in results may be explained by the different ways in which data on academic achievement are collected. Namely, in our research, we collected data on academic achievements through self-reports, while in an earlier study, de Vries and colleagues used data obtained from the official record. In addition, it may be that individuals with higher scores on this personality trait have diminished their achievements. Finally, it is in line with the theoretical presumption that honesty-humility includes modesty domain (Ashton et al., 2014).

In our study, emotionality was unrelated to academic procrastination, contrary to our prediction. However, some previous studies also showed inconsistent results on the relationship between the Big-Five neuroticism and this academic outcome (e.g., Steel et al., 2000; Watson, 2001). Maybe that neuroticism, which explained most of the variance of delaying decisions of small and great importance, is not a significant predictor of academic procrastination (Milgram \& Tenne, 2000). Future studies should test this association on new samples and other measures of academic procrastination. Also, it would be helpful to research the facet level and examine the association between academic procrastination and fearfulness, anxiety, dependence, and sentimentality emotional domains.

As expected, conscientiousness has shown a negative relationship with academic procrastination on the bivariate level and unique predictive power related to this academic outcome. Also, conscientiousness uniquely positively predicted academic performance. Our results are in line with previous findings (e.g., Chamorro-Premuzic \& Furnham, 2003; de Vries et al., 2011; Khan \& Sarwar, 2016; Furnham \& Chamorro-Premuzic, 2004; Noftle \& Robins, 2007), and with theoretical description that conscientiousness encompasses adaptive features such as organisation, self-disciplined, diligence, perfectionism and prudence (Lee \& Ashton, 2004). Furthermore, the tendency to achieve is also positively related to conscientiousness (Anglim et al., 2017), and therefore conscientiousness has a positive impact on various aspects of success in the academic and work environment.

On a bivariate level, psychological distress, which includes negative emotional states such as anxiety, depression, and stress, was unrelated to academic procrastination. However, results of hierarchical regression analysis indicated 
that psychological distress positively predicted academic procrastination, which is in line with our prediction. This result is also consistent with previous findings, which demonstrated a positive relationship between academic procrastination and negative affective consequences and negative emotional states (e.g., Grunschel et al., 2013a; Pychyl et al., 2000; Tice \& Baumeister, 1997). Given the significant prevalence of academic procrastination among student populations at all levels of study (He, 2017; Constantion et al., 2018) it should be necessary for future research to examine other psychological and socioeconomic predictors of this harmful, widespread phenomenon. As we can see from the results of our study, there is a significant negative association between academic procrastination and academic performance, indicating that procrastination reduces the ability to perform student duties.

This study also examined whether HEXACO personality traits outperformed psychological distress in predicting academic procrastination and academic performance. As expected, the result of hierarchical regressions analyses showed incremental validity of the HEXACO personality traits in predicting academic procrastination and academic performance. It has been shown that HEXACO dimensions in third step regression analyses explained $24 \%$ of the variance in academic procrastination and $13 \%$ of the variance in academic procrastination. Conscientiousness had a more substantial contribution to explaining academic procrastination and academic performance. Given that the dimension of emotionality greatly overlaps with the core of psychological distress, emotionality did not significantly affect the prediction of any academic outcomes in our study.

\subsection{Limitation and Future Directions}

Although this study assesses the contribution of the HEXACO dimensions and psychological distress in significant academic outcomes (procrastination and achievement) and has a valuable endowment to the field, it has some limitations. The use of a self-report measures could be influenced by social desirability, especially regarding personality traits and data about academic achievement. Academic procrastination should be measured using behavioural measures and official data to study success. Also, in this s study, psychological distress was measured as a unitary construct so it remains unclear the relations between the individual components of this construct and the measured academic outcomes. The generalization of findings may be limited to specific populations since participants from this study are from one European country, and the majority was Caucasian. Therefore, further research is needed to examine student populations in other countries and other cultures. A comparison of students in private and public higher education would provide useful data on targeted interventions to prevent poor outcomes of academic procrastination.

\subsection{Theoretical, Research, and Practical Implications}

The findings of this study have specific practical implications for further research and practice. Academic procrastination is a widespread phenomenon present at all higher education levels (graduate, undergraduate and postgraduate), it is crucial to building an academic climate that boosts self-confidence and helps students organize student commitments. This includes the involvement of the academic leadership of higher education institutions as well as teaching staff and experts from other fields (psychologists, pedagogues) who will systematically work on strengthening students' mental capacities and overcoming obstacles that lead to procrastination. Indeed, the potential in the student community itself should not be overlooked, and it refers to senior students who could help their younger colleagues in a better organization of learning and fulfilment of other student duties. The assistance of the academic community and society as a whole is especially needed by international students and students with various physical and mental disabilities.

\section{References}

Abbasi, I. S., \& Alghamdi, N. G. (2015). The Prevalence, Predictors, Causes, Treatment, and Implications of Procrastination Behaviors in General, Academic, and Work Setting. International Journal of Psychological Studies, 7(1), 59-66. https://doi.org/10.5539/ijps.v7n1p59

Alexander, E. S., \& Onwuegbuzie, A. J. (2007). Academic procrastination and the role of hope as a coping strategy. Personality and Individual Differences, 42(7), 1301-1310. https://doi.org/10.1016/j.paid.2006.10.008

Allik, J., \& Realo, A. (1997). Intelligence, academic abilities, and personality. Personality and Individual Differences, 23(5), 809-814. https://doi.org/10.1016/S0191-8869(97)00103-7

Anglim, J., Knowles, E. R. V., Dunlop, P. D., \& Marty, A. (2017). HEXACO Personality and Schwartz's Personal Values: A Facet-Level Analysis. Journal of Research in Personality, 68, 23-31. https://doi.org/10.1016/j.jrp.2017.04.002

Ashton, M. C., \& Lee, K. (2007). Empirical, theoretical, and practical advantages of the HEXACO model of personality structure. Personality and Social Psychology Review, 11, 150-166. 
https://doi.org/10.1177/1088868306294907

Ashton, M. C., \& Lee, K. (2009). The HEXACO-60: A short measure of the major dimensions of personality. Journal of Personality Assessment, 91(4), 340-345. https://doi.org/10.1080/00223890902935878

Ashton, M. C., Lee, K., \& De Vries, R. E. (2014). The HEXACO honesty-humility, agreeableness, and emotionality factors: A review of research and theory. Personality and Social Psychology Review, 18(2), 139-152. https://doi.org/10.1177/1088868314523838

Babarović, T., \& Šverko, I. (2013). The HEXACO Personality Domains in the Croatian Sample. Društvena istraživanja, 22(3), 397-411. https://doi.org/10.5559/di.22.3.01

Balkıs, M. (2011). Academic efficacy as a mediator and moderator variable in the relationship between academic procrastination and academic achievement. Ĕgitim Araştırmaları Dergisi, 45, 1-16.

Balkis, M., \& Duru, E. (2007). The Evaluation of the Major Characteristics and Aspects of the Procrastination in the Framework of Psychological Counseling and Guidance. Educational Sciences: Theory and Practice, 7(1), 376-385.

Brody, N. (2000). History of theories and measurements of intelligence. In R. J. Sternberg (Ed.), Handbook of intelligence (pp. 16-33). New York: Cambridge University Press.

Casini, E., Preti, E., Sergi, I., Gnisci, A., \& Richetin, J. (2018). Predictive Validity of the Three-Factor Model of Impulsivity for Risky Behaviors. Journal of Personality Assessment. https://doi.org/10.1080/00223891.2018.152379

Chamorro-Premuzic, T., \& Furnham, A. (2003). Personality traits and academic examination performance. European Journal of Personality, 17(3), 237-250. https://doi.org/10.1002/per.473

Chamorro-Premuzic, T., \& Furnham, A. (2003a). Personality predicts academic performance: Evidence from two longitudinal university sample, Journal of Research in Personality, 37(4), 319-339. https://doi.org/10.1016/S0092-6566(02)00578-0

Constantin, K., English, M. M., \& Mazmanian, D. (2018). Anxiety, depression, and procrastination among students: Rumination plays a larger mediating role than worry. Journal of Rational-Emotive \& Cognitive-Behavior Therapy, 36(1), 15-27. https://doi.org/10.1007/s10942-017-0271-5

Costa, P. T., \& McCrae, R. R. (1992). Professional manual: Revised NEO Personality Inventory (NEO-PI-R) and NEO Five-Factor Inventory (NEO-FFI). Odessa, FL: Psychological Assessment Resources.

de Vries, A., de Vries, R. E., \& Born, M. P. (2011). Broad versus narrow traits: conscientiousness and honesty humility as predictors of academic criteria. European Journal of Personality, 25(5), 336-348. https://doi.org/10.1002/per.795

Dollinger, S., \& Orf, L. (1991). Personality and performance in "personality:" Conscientiousness and openness. Journal of Research in Personality, 25, 276-284. https://doi.org/10.1016/0092-6566(91)90020-Q

Fernie, B. A., Bharucha, Z., Nikčević, A. V., Marino, C., \& Spada, M. M. (2017). A metacognitive model of procrastination. Journal of Affective Disorders, 210, 196-203. https://doi.org/doi:10.1016/j.jad.2016.12.042.

Ferrari, J. R., \& Díaz-Morales, J. F. (2014). Procrastination and mental health coping: A brief report related to students. Individual Differences Research, 12(1), 8-11.

Ferrari, J. R., \& Scher, S. J. (2000). Toward an understanding of academic and nonacademic tasks procrastinated by students: The use of daily logs. Psychology in the Schools, 37, 359-366. https://doi.org/doi:10.1002/1520-6807(200007)37:4

Furnham, A., \& Chamorro-Premuzic, T. (2004). Personality and intelligence as predictors of statistics examination grades. Personality \& Individual Differences, 37, 943-957. https://doi.org/10.1016/j.paid.2003.10.016

Furnham, A., Chamorro-Premuzic, T., \& McDougall, F. (2002). Personality, cognitive ability, and beliefs about intelligence as predictors of academic performance. Learning \& Individual Differences, 14, 47-65.

Goldberg, L. R. (1990). An alternative "description of personality": The Big-Five factor structure. Journal of Personality and Social Psychology, 59, 1216-1229.

Goldberg, L. R. (1993). The structure of phenotypic personality traits. American Psychologist, 48, 26-34.

Goroshit, M. (2018). Academic procrastination and academic performance: An initial basis for intervention. Journal of Prevention \& Intervention in the Community, 46(2), 131-142. 
https://doi.org/10.1080/10852352.2016.1198157

Grunschel, C., Patrzek, J., \& Fries, S. (2013). Exploring reasons and consequences of academic procrastination: An interview study. European Journal of Psychology of Education, 28, 841-861. https://doi.org/10.1007/s10212-012-0143-4

Gupta, R., Hershey, D., \& Gaur, J. (2012). Time perspective and procrastination in the workplace: An empirical investigation. Current Psychology, 31(2), 195-211.

He, S. C. (2017). A Multivariate Investigation into Academic Procrastination of University Students. Open Journal of Social Sciences, 5, 12-24. https://doi.org/10.4236/jss.2017.510002

Hen, M., \& Goroshit, M. (2014). Academic procrastination, emotional intelligence, academic self-efficacy, and GPA: A comparison between students with and without learning disabilities. Journal of Learning Disabilities, 47(2), 116-124. https://doi.org/10.1177/0022219412439325

Irfan, S., Khizar, U., Murtaza, S., \& Iftakhar, I. (2015). Relationship among personality traits, procrastination and coping strategies. International Journal of Advanced Research, 3(11), 184-193.

Jensen, A. R. (1980). Uses of sibling data in educational and psychological research. American Educational Research Journal, 17, 153-170.

Khan, S. R., \& Sarwar, S. M. (2016). The HEXACO Personality Inventory and Academic Performance in MIS Course. Journal of Applied Environmental and Biological Sciences, 26(3S), 175-183.

Kim, K. R., \& Seo, E. H. (2015). The relationship between procrastination and academic performance: A Meta-analysis. Personality and Individual Differences, 82, 26-33. https://doi.org/10.1016/j.paid.2015.02.038

Kuncel, N. R., Hezlett, S. A., \& Ones, D. S. (2001). A comprehensive meta-analysis of the predictive validity of the graduate record examinations: Implications for graduate student selection and performance. Psychological Bulletin, 127, 162-181. https://doi.org/10.1037/0033-2909.127.1.162

Lay, C., \& Silverman, S. (1996). Trait Procrastination, Anxiety, and Dilatory Behavior. Personality and Individual Differences, 21, 61-67. https://doi.org/10.1016/0191-8869(96)00038-4

Lee, K., \& Ashton, M. C. (2004). Psychometric properties of the HEXACO Personality Inventory. Multivariate Behavioral Research, 39, 329-358. http://doi.org/10.1207/s15327906mbr3902_8

Lee, K., \& Ashton, M. C. (2008). The HEXACO personality factors in the indigenous personality lexicons of English and 11 other languages. Journal of Personality, 76, 1001-1053. https://doi.org/10.1111/j.1467-6494.2008.00512.x

Lovibond, S. H., \& Lovibond, P. F. (1995). Manual for the Depression Anxiety Stress Scales (2nd ed.). Sydney: Psychology Foundation.

Mahmood, M., Frolova, Y., \& Gupta, B. (2021). The HEXACO, academic motivation and learning approaches: evidence from a central Asian country. Education + Training, 63(6), 920-938. https://doi.org/10.1108/ET-11-2019-0257

McCrae, R. R., \& Costa, P. T., Jr. (1987). Validation of the Five-factor model of personality across instruments and observers. Journal of Personality and Social Psychology, 52(1), 81-90. https://doi.org/10.1037/0022-3514.52.1.81

Milgram, N., \& Tenne, R. (2000). Personality correlates of decisional and task avoidant procrastination. European $\begin{array}{llrl}\text { Journal of Personality, } & 14(2),\end{array}$ https://doi.org/10.1002/(SICI)10990984(200003/04)14:2\%3C141::AID-PER369\%3E3.0.CO;2-V

Milgram, N., Mey-Tal, G., \& Levison, Y. (1998). Procrastination, generalized or specific, in college students and their parents. Personality and Individual Differences, 25, 297-316.

Nguyen, B., Steel, P., \& Ferrari, J. R. (2013). Procrastination's impact in the workplace and the workplace's impact on procrastination. International Journal of Selection \& Assessment, 21(4), 388-399. https://doi.org/10.1111/ijsa.12048

Noftle, E. E., \& Robins, R. W. (2007). Personality predictors of academic outcomes: Big five correlates of GPA and SAT scores. Journal of Personality and Social Psychology, 93(1), 116-130. https://doi.org/10.1037/0022-3514.93.1.116

Pychyl, T. A., Lee, J. M., Thibodeau, R., \& Blunt, A. (2000). Five days of emotion: An experience sampling study of 
undergraduate student procrastination. Journal of Social Behavior \& Personality, 15, 239-254.

Rabin, L. A., Fogel, J., \& Nutter-Upham, K. E. (2011). Academic procrastination in college students: The role of self-reported executive function. Journal of Clinical and Experimental Neuropsychology, 33(3), 344-357. https://doi.org/10.1080/13803395.2010.518597

Rosário, P., Costa, M., Núñez, J. C., González-Pienda, J., Solano, P., \& Valle, A. (2009). Academic procrastination: Associations with personal, school, and family variables. The Spanish Journal of Psychology, 12(1), 118-127. https://doi.org/10.1017/S1138741600001530

Sandhya, M., \& Gopinath, T. (2019). The Relationship Study of Big Five Model Of Personality and Procrastination among Young Adults. IOSR Journal of Humanities and Social Science (IOSR-JHSS), 24(8), 44-55, https://doi.org/10.9790/0837-2408074455

Schouwenburg H. C., \& Lay, C. H. (1995). Trait procrastination and the big-five factors of personality. Personality and Individual Diferences, 18(4), 481-490. https://doi.org/10.1016/0191-8869(94)00176-S

Schouwenburg, H. C., Lay, C. H., Pychyl, T. A., \& Ferrari, J. R. (2004). Counseling the procrastinator in academic settings. American Psychological Association.

Sirois, F., \& Pychyl, T. (2013). Procrastination and the priority of short-term mood regulation: Consequences for future self. Social and Personality Psychology Compass, 7(2), 115-127. https://doi.org/10.1111/spc3.12011

Sokić, K, Horvat, Đ., \& Krakan, I. (2019). HEXACO personality traits as predictors of impulsive buying in men and women. Interdisciplinary Management Research XV Conferences' proceedings, 1, 621-636.

Steel, P. (2007). The nature of procrastination: A meta-analytic and theoretical review of quintessential self-regulatory failure. Psychological Bulletin, 133, 65-94. https://doi.org/10.1037/0033-2909.133.1.65

Steel, P., \& Ferrari, J. (2013). Sex, education and procrastination: An epidemiological study of procrastinators' characteristics from a global sample. European Journal of Personality, 27(1), 51-58. https://doi.org/10.1002/per.1851

Steel, P., \& Klingsieck, K. B. (2016). Academic procrastination: Psychological antecedents revisited. Australian Psychologist, 51(1), 36-46. https://doi.org/10.1111/ap.12173

Steel, P., Brothen, T., \& Wambach, C. (2000). Procrastination and personality, performance and mood. Personality \& Individual Differences, 30, 95-106. https://doi.org/10.1016/S0191-8869(00)00013-1

Svartdal, F., Dahl, T. I., Gamst-Klaussen, T., Koppenborg, M., \& Klingsieck, K. B. (2020). How Study Environments Foster Academic Procrastination: Overview and Recommendations. Front Psychol., 540910. https://doi.org/10.3389/fpsyg.2020.540910

Tice, D. M., \& Baumeister, R. F. (1997). Longitudinal Study of Procrastination, Performance, Stress, and Health: The Costs and Benefits of Dawdling. Psychological Science, 8, 454-458. https://doi.org/10.1111/j.1467-9280.1997.tb00460

Van E., W. (2003). A meta-analytically derived nomological network of procrastination. Personality and Individual Differences, 35(6), 1401-1418. https://doi.org/10.1016/s0191-8869(02)00358-6

Watson, D. C. (2001). Procrastination and the five-factor model: A facet level analysis. Personality and Individual Differences, 30(1), 149-158. https://doi.org/10.1016/S0191-8869(00)00019-2

Wohl, M. J., Pychyl, T. A., \& Bennett, S. H. (2010). I forgive myself, now I can study: How self-forgiveness for procrastinating can reduce future procrastination. Personality and Individual Differences, 48(7), 803-808. https://doi.org/10.1016/j.paid.2010.01.029

Zeidner, M., \& Matthews, G. (2000). Intelligence and personality. In R. Sternberg (Ed.), Handbook of intelligence (pp. 581-610). New York: Cambridge University Press.

\section{Copyrights}

Copyright for this article is retained by the author(s), with first publication rights granted to the journal.

This is an open-access article distributed under the terms and conditions of the Creative Commons Attribution license (http://creativecommons.org/licenses/by/4.0/). 